\title{
ФАКТОРЫ, ВЛИЯЮЩИЕ НА КОМПЛАЕНТНОСТЬ ПОДРОСТКОВ, ПОЛУЧАЮЩИХ ЛЕЧЕНИЕ ПО ПОВОДУ САХАРНОГО ДИАБЕТА
}

\author{
Хуснуллина E.B.
}

ФГБУ «Национальный медицинский исследовательский центр им. В.А. Алмазова» Минздрава РФ, Санкт-Петербург

АКТУАЛЬНОСТь: сахарный диабет 1 типа (СД1) - одно из наиболее распространенных эндокринологических заболеваний, которое ассоциировано с изменением образа жизни пациента, постоянным самоконтролем гликемии, соблюдением строгого режима терапии в течение всей жизни. По сравнению с другими возрастными группами, подростки с СД1 имеют больший риск ухудшения гликемического контроля и плохого соблюдения режима терапии из-за психосоциальных и физиологических особенностей.

ЦЕЛЬ: изучение факторов влияния на комплаентность подростков, получающих лечение по поводу СД1.

МАТЕРИАЛЫ И МЕТОДЫ: ВКлючено 58 пациентов от 12 до 17 лет с СД1. Проведено анкетирование, включавшее 6 валидных опросников, позволивших оценить уровень комплаентности, качество жизни, уровень стресса, вызванного СД1, определить личностные характеристики пациентов. Также оценивался уровень гликозилированного гемоглобина $\left(\mathrm{Hb}_{1 c}\right)$. Статистический анализ проводился с помощью программного обеспечения «јаmovi».

РЕЗУЛЬТАТЫ: выборка распределилась на 3 группы - компенсации ( $\mathrm{n}=14)$, субкомпенсации $(\mathrm{n}=21)$ и декомпенсации $(n=23)$, согласно целевым значения $\mathrm{HbA}_{1 c}$ (Медиана $\mathrm{HbA}_{1 c}-6,6 \% ; 8,1 \%$; 11,2\% соответственно). Выявлена зависимость $\mathrm{HbA}_{1 с}$ от степени комплаентности, с более высоким уровнем в группе

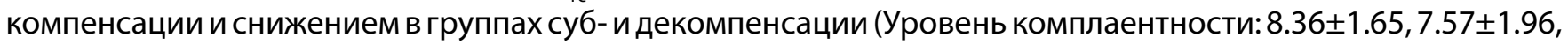
6.65 $\pm 1.92 ; p<.001)$. Установлено, что частый самоконтроль гликемии, ассоциирован с высоким уровнем комплаентности и снижением $\mathrm{HbA}_{1 с}$ (Средний уровень комплаентности и уровнь $\mathrm{HbA}_{1 c}$ : до 5 раз в день -

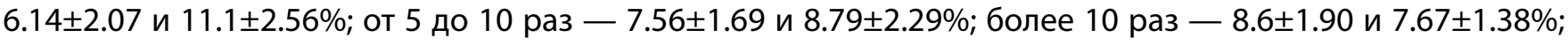
p <0.01), вследствие чего дети, использовавшие для самоконтроля сенсор непрерывного мониторинга гликемии, имели достоверно более низкий $\mathrm{HbA}_{1 с}$ (глюкометр - 9.54 2.63 ; сенсор - 7.72 $\pm 1.15 ; \mathrm{p}=0.02$ ). Выявлена прямая положительная связь комплайнса и уровня качества жизни ( $<$.001), а именно внутренней картины болезни (ВКБ). Анализ уровня стресса, вызванного СД1, показал отрицательное влияние на ВКБ, и как следствие снижение комплайнса $(p<0,02)$. Выявлены свойства «комплаентной личности» теплота в общении, доверчивость, высокий уровень самоконтроля, аккуратность, ответственность, предусмотрительность, а также самодостаточность ( $<0.05)$. Проанализированы возрастные особенности более старшим детям свойственен выраженный дистресс и, как следствие, снижение комплайнса (Уровень

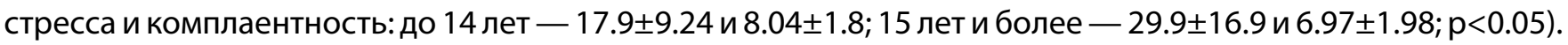
Прямого влияния пола на комплайнс выявлено не было, однако у девочек отмечалась более негативная ВКБ ( $p=0.04)$. Также выявлены личностные особенности женского пола - эмоциональная неустойчивость, тревожность, депрессивность, экспрессивность, что так же ухудшает комплайнс $(p<0.05)$

ВЫвОды: высокий уровень комплаентности и частота контроля гликемии способствует компенсации СД1. Уровень дистресса, вызванного СД1, ухудшает внутреннюю картину болезни, снижает качество жизни, уровень комплаентности, степень гликемического контроля, что ведет к скорейшей декомпенсации заболевания. Необходим персонифицированный подход к лечению пациентов с СД1 с учетом особенностей личности. 